\title{
Balkanologie
}

Balkanologie Revue d'études pluridisciplinaires

Vol. VI, $n^{\circ}$ 1-2 | 2002

Volume VI Numéro 1-2

\section{Glamočak (Marina), La transition guerrière yougoslave}

Paris : L'Harmattan, 2002, 287 p.

\section{Diane Masson}

\section{(2) OpenEdition}

Journals

Édition électronique

URL : http://journals.openedition.org/balkanologie/1772

DOI : $10.4000 /$ balkanologie. 1772

ISSN : 1965-0582

Éditeur

Association française d'études sur les Balkans (Afebalk)

Édition imprimée

Date de publication : 1 décembre 2002

Pagination : 273-274

ISSN : 1279-7952

Référence électronique

Diane Masson, «Glamočak (Marina), La transition guerrière yougoslave », Balkanologie [En ligne], Vol. VI, n 1-2 | 2002, mis en ligne le 04 février 2009, consulté le 17 décembre 2020. URL : http://

journals.openedition.org/balkanologie/1772 ; DOI : https://doi.org/10.4000/balkanologie.1772

(c) Tous droits réservés 
deux exemples de ces intellectuels hybrides, produits mi-paysans : Dobrica Ćosić et Franjo Tudjman (p. 87), dont la comparaison est intéressante.

I. Iveković produit quelques rappels sur l'économie souterraine (corollaire de l'industrialisation ?), qui n'existe pas que dans les pays de l'Est, mais aussi dans les pays dits " développés n (p. 61). Il insiste sur les conditions sociales et économiques. Il analyse le jeu des élites, et leurs perceptions de leurs propres intérêts et rappelle que les Balkans et le Caucase vivent toujours dans la temporalité de la transition de la société agraire à la société industrielle (p.15o). Il revient sur quelques " pompiers pyromanes " quand il affirme que la reconnaissance internationale a, en fait, légitimé l'autorité ethnocratique, les pratiques de développement et de la violence nationalitaires étatiques (p.169); et pose la question de qui a le droit à l'autodétermination et quelles en sont les conséquences pour les autres groupes ou les droits individuels (p. 179) ? En fait, conclue-t-il, les Etats occidentaux ne se sont pas préoccupé des critères utiles à la construction des Etats post-communistes.

On trouve, forcément, quelques erreurs : Stepinec (p. 136), Karadžić au lieu de Milošević (p. 138). Le seul point faible est l'effet " boule neige " évoqué, les régimes communistes s'écroulant les uns après les autres (p. 167), raccourci analytique certainement dû au fait que cette problématique dépassait le cadre de son étude. Ces deux " laboratoires régionaux " présentent des traits similaires, des évolutions parallèles, des perspectives qui se ressemblent. I. Iveković démontre brillamment que la modernisation communiste a atteint ses limites quantitatives et qualitatives, cédant la place à la stagnation économique et à la crise, vecteur de troubles sociaux et crises identitaires qui ont initié une nouvelle dynamique sociale et politique qui a conduit à l'homogénéisation et à la polarisation nationales aboutissant à la fragmentation de la Yougoslavie et de la fédération soviétique en de multiples Etats natio$\operatorname{naux}$ (p. 31).

Patrick Michels

\author{
Glamočak (Marina), \\ La transition guerrière yougoslave, \\ Paris : L'Harmattan, 2002, $287 \mathrm{p}$.
}

"L'ouvrage de Marina Glamočak, tiré de sa thèse, richement documenté, va faire date parce qu'il remonte aux causes de la décomposition sanglante de l'ex-Yougoslavie " (p. 7). Cette première phrase de la préface d'Alain Joxe résume parfaitement la démarche intellectuelle de M. Glamočak. Sociologue, l'auteur a voulu sortir des cadres "étriqués" des théories existantes sur la " transition à la démocratie " et proposer une grille de lecture différente de l'éclatement de la Fédération yougoslave. Son postulat de départ est que " malgré les conflits guerriers, la transition yougoslave n'est pas séparable de la question du passage des anciens régimes socialistes au capitalisme. La guerre intérieure yougoslave, causée par des liens inextricables entre le processus de transition (que ce soit son acceptation ou son refus) et l'aspiration à l'indépendance, n'est qu'une des voies qu'emprunte la transition n (p. 20).

Dans la première partie l'ouvrage, l'auteur revient sur " les clivages sociaux et le multipartisme dans la société ex-yougoslave ", étude préliminaire indispensable à la compréhension des événements ultérieurs. L'originalité de cette étude du "prélude" à la guerre réside dans l'intérêt qui est porté à la structure même de la société yougoslave et aux rapports des différentes classes sociales en son sein, en s'interrogeant sur la capacité de celle-ci à répondre aux " besoins du multipartisme ". L'héritage politique du régime titiste est également 
traité, mettant en lumière la division de la population yougoslave en " cages nationales " (p. 58), circonstances qui auront un rôle déterminant au moment de la création de premiers partis politiques.

La deuxième partie est centrée plus précisément sur le " multipartisme et la transition politique en Croatie et en Serbie ", avec une présentation du multipartisme est-européen. Malgré les différences des sociétés serbe et croate, force est de constater une similitude dans le sort que ces dernières subissent, à savoir une désintégration et une segmentation, face à des institutions étatiques qui " se bornent à assurer le pouvoir et ne proposent aucune intégration sociale exceptée celle de la nation en guerre $n$ (p. 110).

La troisième partie, qui est selon nous la plus riche, est consacrée aux " rapports entre pouvoir et groupes militaires et paramilitaires ". L'auteur revient sur la décomposition de l'Armée populaire yougoslave (JNA) et démêle avec brio les liens politico-financiers qui ont permis le financement de l'armement dans les deux républiques yougoslaves, ainsi que l'avènement des armées républicaines nationales et des groupes paramilitaires.

Enfin, dans une quatrième partie, les " conséquences de la transition guerrière n sont exposées, toujours dans une approche comparative entre la Serbie et la Croatie. Des questions comme le nationalisme populiste en Serbie, ou le rôle prééminent de l'Etat dans la construction et la consolidation du régime croate sont décortiquées, éléments parmi d'autres qui empêchent les deux républiques de " rejoindre un processus pacifiste de transition politique et économique " (p. 269).

La transition guerrière yougoslave est par conséquent un ouvrage important pour la compréhension de la désintégration de l'ancienne fédération titiste. De manière plus globale, son approche méthodologique, qui sort des schémas classiques de lecture du concept de "transition ", ouvre la voie à de nouvelles pistes de recherche sur le passage à la démocratie.

Diane Masson

\author{
Kaser (Karl], Pichler [Robert), \\ Schwandner-Sievers [Stephanie], Hg., \\ Die weite Welt und das Dorf. \\ Albanische Emigration am Ende des 20. Jahrhunderts, \\ Wien : Böhlau, 2002, 296 p.
}

L'émigration est l'une des réalités les plus marquantes de la société albanaise depuis la chute du régime communiste. Entre 1990 et $1998,16 \%$ de la population de l'ex-pays d'Enver Hoxha auraient émigré, temporairement ou non. Aujourd'hui, on avance les chiffres de près de 500000 migrants albanais en Grèce, de plus de 150000 en Italie et de plusieurs milliers d'autres en Allemagne, aux Etats-Unis, au Canada, en Belgique, en Turquie ou en France (pour une population de 3300 ooo habitants en 1990). Le livre collectif édité par Karl Kaser, Robert Pichler et Stephanie Schwandner-Sievers, qui s'intéresse à ce phénomène et à ses conséquences, est donc important, d'autant que les auteurs ont su, à partir d'une étude de cas, avec toute sa richesse et sa précision, proposer une analyse plus large du phénomène en y adjoignant d'autres études. Le noyau de l'ouvrage est en effet le fruit d'un travail anthropologique mené, en été 1998 , dans deux villages du sud de l'Albanie, situés dans la région montagneuse du Kurvelesh (à l'ouest de Gjirokastër) - en l'occurrence Fterra et Çorraj. Aux 